\title{
Entre milagros, prodigios, maravillas, portentos y favores: san Pedro Nolasco y el certamen poético mexicano de 1633
}

\author{
Among Miracles, Wonders, Marvels, Portents \\ and Favors: St. Peter Nolasco \\ and the 1633 Mexican Poetry Contest
}

\author{
Jessica C. Locke \\ Universidad Nacional Autónoma de México \\ Instituto de Investigaciones Filológicas \\ Centro de Poética \\ jes_locke@hotmail.com
}

\section{Resumen}

En este artículo se estudian las nociones de milagro, prodigio, maravilla, portento y favor de acuerdo con el uso de estos términos en el manuscrito que contiene el certamen poético mexicano de 1633 en honor a san Pedro Nolasco. Se examina su empleo en los primeros siete concursos del certamen, así como en la convocatoria y en los textos introductorios y complementarios escritos por el secretario del evento poético, fray Juan de Alavés, y se relacionan los sucesos poetizados en estos concursos con los episodios hagiográficos y/o los hechos históricos correspondientes. Asimismo, se dan a conocer algunas muestras de la poesía ganadora y de los textos en prosa del certamen en las que aparece dicha terminología, con el fin de señalar cómo ésta sirve para subrayar los mensajes implícitos en todo el manuscrito: sobre la grandeza de Nolasco, el favor divino del que gozaba y los méritos que lo hicieron digno de ser canonizado, lo cual se había logrado en 1628. El presente artículo constituye un derivado del trabajo de edición, estudio, análisis e investigación realizado para la preparación de la edición crítica del certamen.

\section{Palabras clave}

Certamen poético, san Pedro Nolasco, milagro, prodigio, maravilla, portento, favor.

\section{AbSTRACT}

In this article, we study the notions of milagro, prodigio, maravilla, portento and favor (miracle, wonder, marvel, portent in its positive sense, and favor) in accordance with the use of these terms in the manuscript that contains the 1633 Mexican poetry contest in honor of St. Peter Nolasco. We study their use in the first seven competitions within the con- 
test, as well as in the call for participants for the competitions and in the introductory and complementary texts written by friar Juan de Alavés, the secretary of the contest, and we relate the events that are poeticized in the competitions with their corresponding hagiographical and/or historical circumstances. We also include examples of the contest's winning poetry and of the prose texts from the manuscript in which the five above-mentioned terms are included, in order to show how these terms serve to underscore the messages that are implicit throughout the manuscript, regarding Nolasco's greatness, his enjoyment of divine grace, and the merits that had made him worthy of having been canonized, which had been achieved in 1628. This article represents a by-product of the project that consisted of editing, studying, analyzing and doing research on the contest in order to prepare the critical edition of the manuscript.

\section{KEYWORDS}

Poetry contest, St. Peter Nolasco, miracle, wonder, marvel, portent, favor.

RECEPCIÓN: 22/01/2019

ACEPTACIÓN: 13/02/2019

$\mathrm{E}$ n los últimos meses de 1628, se dio una magna noticia para la Orden de la Merced: por fin se había logrado la canonización de su santo fundador. ${ }^{1}$ De manera casi inmediata, se empezaron a planear fiestas celebratorias en Madrid, las cuales se realizaron en el transcurso de 1629. 2 También en México, donde, en el siglo XVII, la Orden de la Merced vivía una época de gran expansión y creciente influencia, se quiso festejar en grande la noticia, pero una fuerza sobrehumana - la naturaleza - lo impidió por un tiempo. En 1629, sucedió una de las inundaciones más devastadoras en la historia de México, por lo que los mercedarios en estas tierras tuvieron que esperar más de cuatro años después de la canonización del santo fundador de su orden para poder llevar a cabo los festejos.

1 "La canonización de Pedro Nolasco tuvo dos momentos importantes. Primero, el 30 de septiembre de 1628, la Congregación de Ritos [...] reconoce el culto inmemorial de Pedro Nolasco. En consecuencia, el papa Urbano VIII concede poder celebrar el oficio y misa para la familia mercedaria. Esto sería la llamada 'beatificación equipolente', según terminología del papa Benedicto XIV" ("Hoy celebramos el Día...": s. p.).

${ }^{2}$ Como explica Cécile Vincent-Cassy, "los mercedarios descalzos de Madrid fueron los primeros en festejar el acontecimiento, en su iglesia Santa Bárbara, durante cuatro días, en torno al 29 de enero [el día de la fiesta del santo, y] desde el 21 hasta el 30 de abril del mismo año, los mercedarios calzados organizaron sus propias celebraciones con especial fasto" (s. p.). La autora también menciona los festejos que se hicieron en las ciudades de Salamanca, Valladolid y Zaragoza con motivo de la canonización de Nolasco. 
Pedro Nolasco nació alrededor de 1180 en Mas-Saintes-Puelles en el Languedoc (García: 33). Hay poca información sobre su juventud, pero algunas fuentes sostienen que fue en su adolescencia cuando decidió dedicar su vida al servicio de la Iglesia católica ${ }^{3}$ y que a los 20 años, aproximadamente, llegó a Barcelona para iniciar su obra caritativa y su labor como redentor de cautivos. ${ }^{4}$ Se piensa que su convicción respecto a la necesidad de una orden dedicada a dicha labor fue favorecida tanto por una visión que tuvo en 1218, en la cual la Virgen le pidió que fundara la orden, como por las apariciones de la Virgen al rey Jaime I de Aragón y a san Raimundo de Peñafort, en las que les comunicó la misma petición. ${ }^{5}$ La orden se fundó el 10 de agosto de ese año y fue confirmada por el papa Gregorio IX, quien hizo "a san Pedro Nolasco Maestre General de la Orden, ateniéndose a la constitución militar de la Orden Mercedaria" (García: 36). Pedro Nolasco murió en 1256 en Barcelona. En la tradición histórica en torno al santo, se destacan no sólo su labor como redentor, sino también su acompañamiento a Jaime I en la conquista de Mallorca y de Valencia y a Fernando III en la reconquista de Sevilla; este último suceso figuró como tema en el certamen poético mexicano de 1633.

El mercedario fray Juan de Alavés fungió como autor de la relación de las fiestas de dicho año y como secretario del certamen. ${ }^{6}$ El manuscrito titulado Relación histo-

3 "Se cree que cuando tenía alrededor de 15 años murió su padre, dejándole una cuantiosa herencia. No se dejó deslumbrar por ella, sino que se consagró a Dios, haciendo voto de castidad perpetua [...] A los dieciséis años luchó con las armas contra los albigenses, llevando como bandera una imagen de la Virgen" (García: 34).

${ }^{4}$ Diversas fuentes proponen que llegó a Barcelona a los 22 años: el propio Juan de Alavés, secretario del certamen poético, ofrece ese dato en la introducción al Libro segundo de la relación de las fiestas (1633b: f. 1v); Pedro Francisco García Gutiérrez lo afirma también en su artículo "Iconografia mercedaria", aunque reconoce que no todos los testimonios concuerdan al respecto: "A los veintidós años se cree que llegó a Barcelona. Antes pasó por Montserrat, en cumplimiento de una promesa, donde estuvo varios días en oración y penitencia [...] En cuanto a la fecha exacta de su llegada a Barcelona, tampoco hay unanimidad; las distintas fechas oscilan entre 1205 y 1213 ” (34).

5 "After mature deliberation, moved also by a heavenly vision, he resolved to found a religious order (1218) [...] whose chief object would be the redemption of Christian slaves. In this he was encouraged by St. Raymond Penafort and James I, King of Aragon, who, it seems, had been favored with the same inspiration" ["después de deliberar con madurez, también movido por una visión celeste, se resolvió a fundar una orden religiosa (1218) [...] cuyo objeto principal sería la redención de esclavos cristianos. En esto fue apoyado por san Raimundo de Peñafort y Jaime I, rey de Aragón, quienes, al parecer, fueron favorecidos con la misma inspiración"] (Allaria: s. p. Las traducciones de este artículo son mías). Para más circunstancias y detalles sobre la visión que tuvo Nolasco, véase García: 35.

${ }^{6}$ José Mariano Beristáin de Souza ofrece, relativamente, amplios datos sobre fray Alavés en su Biblioteca hispanoamericana septentrional (1816), algunos de ellos bastante curiosos: "Natural de México, donde recibió el hábito del Real Militar Orden de la Merced. Fue de tan raro y temprano ingenio, y de tanto estudio y erudición, que a los trece años hizo oposición escolástica a la cátedra de Retórica de la Universidad mexicana [...] Pero como los ingenios extraor- 
riada de las solemnes fiestas que se hicieron en la muy noble y leal Ciudad de México al glorioso padre y esclarecido patriarca san Pedro Nolasco, fundador y primer religioso de la Real y Militar Orden de Nuestra Señora de la Merced, Redención de Cautivos contiene, en el Libro primero, la relación de las festividades en su totalidad y, en el Libro segundo, la del evento poético. ${ }^{7}$

En el primer libro, Alavés alude al "gozo grande y regocijo desigual" (1633a: f. 8v) que representó la noticia de la canonización, pero explica que la orden no pudo llevar a cabo la celebración debido a las condiciones climatológicas del momento. Aunque, de manera general, se considera que hubo una sola inundación en 1629, a la que ya se ha hecho referencia, Alavés sostiene que ocurrieron dos, ambas de grandes dimensiones en ese año y el siguiente:

habiéndose anegado esta ciudad con una poderosa inundación, con fuerzas humanas irreparable, que sobrevino por el mes de septiembre del año pasado de veintinueve [1629], estaba imposibilitada de celebrar fiestas en medio de tantas penas, fueran gustos aguados los que intentara [...] Sucedió esta primera inundación día de san Mateo a veintiuno de septiembre de este dicho año [...] Dilatáronse las fiestas para cuando decreciesen las aguas, y sucedió tan al contrario, que en el mismo día de san Mateo del año de treinta [1630], sobrevino segunda inundación, conque quedó la cuidad lastimada de nuevo; añadiéronse dolores a dolores con la renovación de la primera llaga, y con esta ocasión no se celebraron estas fiestas en todo aquel año ni el siguiente (1633a: ff. $8 \mathrm{v}-9 \mathrm{r}){ }^{8}$

dinarios suelen desgraciarse cuando anticipan sus flores y sus frutos, nuestro Alavés perdió el juicio antes de los cuarenta años, llegando al extremo de arrojarse de una ventana al patio del Convento [...] Después de esta caída, no sólo recobró la salud, sino las facultades intelectuales, de modo que pudo continuar en el estudio de las letras y en otros empleos" (39).

${ }^{7}$ Debido a que el rescate de concursos como éste depende tanto de la accesibilidad de los testimonios como de la disposición de los editores modernos de trabajar con ellos, no se ha hecho un rescate y un análisis sistemáticos de los concursos poéticos organizados por órdenes religiosas en la Nueva España. No obstante, se puede afirmar, sin lugar a dudas, que este certamen resulta representativo de una tradición poética mucho más amplia. Como explica Irving Leonard (aunque no sin cierto tono de burla), en la Nueva España, "una antigua institución acrecentó su popularidad. Ésta fue el certamen poético, que en la época barroca, permitió a la élite del México colonial mostrar una supuesta devoción a Euterpe, la musa del verso lírico mediante la manipulación métrica y la gimnasia verbal $[\ldots]$ pocos dejaron de aceptar la magnífica oportunidad que se les ofrecía" (191-193; las cursivas son del autor). Los certámenes poéticos, pues, tenían un papel sociocultural muy significativo en la época virreinal, y no hay manera de negar que, en el México barroco, gran parte de la poesía escrita se hizo en el marco de estos eventos literarios. A medida que se rescaten, editen y estudien los registros de otras justas poéticas, y, en particular, las que tienen como motivo el festejo de santos, se podrá saber mejor en qué consiste la singularidad del certamen de 1633, cómo se compara con otros concursos de homenaje similares, y cuáles eran, a grandes rasgos, algunas de las características generales de concursos en torno a las vidas de los santos.

${ }^{8}$ Se modernizó la ortografía, la puntuación y la acentuación de todas las citas antiguas que aparecen en este artículo, de acuerdo con las normas establecidas en la edición crítica 
Los mercedarios mexicanos determinaron, pues, que "la inundación de esta ciudad no era transitoria sino permanente", por lo que al fin tomaron la "última resolución” de que, inundada la ciudad todavía o no, las fiestas en honor a san Pedro Nolasco se celebrarían en enero de 1633 (1633a: f. 9v). La convocatoria del certamen poético se leyó en público el 7 de enero de ese año, el cual constituyó "el primer acto de la fiesta" (1633a: f. 18r), y la ceremonia de premiación tuvo lugar el 5 de febrero.

En dicha convocatoria, se detallan las bases para el certamen en general, así como los requisitos formales y temáticos para cada uno de los ocho concursos poéticos y el de danza. Los primeros abarcaron diferentes géneros líricos en el siguiente orden: epigramas en latín, décimas, soneto, octavas, canciones, liras, glosas, soneto faceto; ${ }^{9}$ y los resultados se recopilaron, como ya se indicó, en el Libro segundo de la Relación historiada. El certamen se basa en un "curioso discurso astrológico" (1633a: f. 17v) ideado por Alavés, que se centra, por un lado, en la comparación de Nolasco con el dios Apolo en sus diferentes identificaciones y, por otro, en la atribución de cada uno de los primeros siete concursos poéticos a los siete planetas (de acuerdo con el concepto ptolemaico del universo) en el orden en que se creía era su cercanía con la tierra (Luna, Mercurio, Venus, Sol, Marte, Júpiter y Saturno):

En este día, pues, en que su religión ${ }^{10}$ sagrada, con festiva pompa y majestuoso aparato, celebra sus victorias y afama sus triunfos, convoca alegre y placentera a los siete planetas, gobernadores de las siete movibles esferas, para que, saliendo de sus ebúrneos tronos y solios de zafir a gozar de este festejo, celebren los merecimientos raros y portentosas hazañas del vencedor divino que, como candidato romano, viene vestido de blanca toga y argentado velo, en que se significa la candidez de su alma, levantando bandera en público teatro, a cuya sombra se recojan los elegantes, facundos y fecundos poetas que cría y alimenta esta muy noble y leal ciudad mexicana que, agradecida a los amorosos afectos de los hijos de Nolasco, debe celebrar su gloria a banderas desplegadas (Alavés, ¿1632?: 1).

Cada uno de los primeros cinco concursos poéticos, así como el séptimo, se basa en un suceso relacionado con la historia de la vida del santo. El primero recuerda la tradición según la cual, cuando era niño Nolasco, un enjambre de abejas hizo un panal en su mano derecha; el segundo, la visión que tuvo el santo en un sueño, de una oliva cuyo cuidado le encargaron "dos ancianos venerables" (Alavés, ¿1632?: 1); el tercero, el favor que le hizo la Virgen María al santo al asistir por él en el coro de

del manuscrito, las cuales se detallan en el estudio preliminar de dicha edición. Asimismo, se separó "por que" cuando su uso es final y se emplearon cursivas para señalar los subrayados del manuscrito, tal como se observa en esta cita.

9 faceto: "Discreto y chistoso en el hablar y inventar cuentos graciosos. Es voz de poco uso" (Dicc. Aut.).

${ }^{10}$ religión: en este caso, con el sentido de orden religiosa, obviamente la de la Merced. 
Barcelona; el cuarto, el cruce de Nolasco del mar Mediterráneo, desde Argel a Valencia, en menos de diez horas, en un barco roto, sin velas ni remos; y el quinto, la reconquista de Sevilla, en la que participó el santo y entró victorioso a la cuidad al lado del rey Fernando III; y el séptimo, la fundación de la Orden de la Merced. En el sexto concurso poético, se pide que Nolasco solicite auxilio divino para bajar las aguas que tan larga presencia habían tenido ya en la Ciudad de México (desde la inundación del 29). Para el octavo y último concurso poético, de soneto faceto, no se pide explícitamente que las composiciones se relacionen con la historia ni con la hagiografía del santo, por lo que no se considerará en el presente artículo. ${ }^{11}$

La respuesta a la convocatoria, en general, fue magnífica: se entregaron, según Alavés, doscientas composiciones para su evaluación y posible premiación (1633b: f. $3 \mathrm{v}$ ), por lo cual los mercedarios decidieron añadir 17 premios a los 24 ya prometidos en la convocatoria. ${ }^{12}$ De acuerdo con Alavés, se estableció que los mercedarios del Convento Grande de la Merced en la Ciudad de México no concursaran "por dar lugar a que se premien los poetas de fuera, que, como huéspedes, deben ser preferidos, de suerte que fue modestia y compostura no entrar [los mercedarios] composiciones" (1633b: 8r). Por lo tanto, como él explica, todas las poesías entregadas para el certamen las presentaron individuos externos al Convento Grande, aunque hubo un participante anónimo, "padre maestro en Teología de nuestra sagrada religión” (1633b: f. 7r), premiado "en honra" en el concurso de epigrama, pero sin premio material, quien puede o no haber sido fray Juan Ortiz, "secretario de esta provincia de la Nueva España y lector de Teología de este convento de México de nuestra sagrada orden" (1633a: f. 17v). Es posible que la decisión de los mercedarios del Convento Grande de no participar se debiera al propósito de mantener cierta objetividad e imparcialidad en la determinación de los resultados del concurso; asimismo, pudo haber respondido a una intención de mostrar su generosidad hacia aquellos que no pertenecían a su comunidad religiosa y, así, difundir su imagen como una orden próspera e influyente.

La gran elegancia con la que los poetas no-mercedarios elogiaron a san Pedro Nolasco revela no sólo su habilidad poética, sino también su familiarización con aspectos relacionados a las tradiciones en torno a dicho santo. Seguramente, esto se debía, por lo menos en parte, a la fuerte presencia e influencia religiosa y social que había alcanzado la Orden de la Merced en México para la época en la que se realizaron las fiestas por su canonización. Se ha documentado que la llegada de la orden a tierras

${ }^{11}$ En este certamen, sí hay algunas referencias a las tradiciones que prestan sus temáticas a los otros concursos; para leer el concurso completo, véase Alavés, 2019 [en prensa].

${ }^{12}$ Alavés dice, en el f. 5v del Libro segundo, que fueron 16 premios los que se añadieron, pero, al hacer la cuenta de los premios agregados, suman 17: véase el Apéndice III de Alavés, 2019 [en prensa]. 
americanas se remonta a la primera década del siglo XvI (Zúñiga: 9-10); sin embargo, los mercedarios se enfrentaron a muchos obstáculos en su intento por establecerse en la capital del virreinato novohispano durante ese siglo, en cierta medida por las órdenes propiamente evangelizadoras que se encontraban ahí (véase León: 50). No obstante, a partir de la década de 1590, la orden empezó a correr con mayor suerte en dicho intento (León: 112-119), y ya en las primeras décadas del siglo XVII tuvo importantes logros de expansión, pues se fundaron conventos en diversas partes del territorio mexicano $;^{13}$ asimismo, entre 1616 y 1618, se erigió una Provincia mexicana independiente de la Provincia de la Visitación de Guatemala, de la que anteriormente dependía (León: 139-143), y se celebró el primer capítulo provincial en 1620 (León: 140). Fue, pues, en este momento de crecimiento de la orden en la Nueva España que se enmarcaron las fiestas mercedarias mexicanas de 1633.

Los poemas premiados en el certamen, así como el cartel de su convocatoria y los textos en prosa con los que Alavés complementa la poesía ganadora, evocan tradiciones hagiográficas e históricas en las que figuran, de manera fundamental, sucesos extraordinarios, mediante los cuales se justifica o se reitera la santidad del personaje y su lugar privilegiado entre los seres humanos debido a la ejemplaridad de sus virtudes. Así, también, recuerdan lo que Antonio Rubial llama "una literatura de prodigios", ${ }^{14}$ la cual se remonta al medioevo:

A lo largo de la Edad Media se desarrolló en Europa una literatura que tenía como finalidad fundamental narrar los milagros con los que la divinidad había favorecido a los seres humanos, ya sea por medio de sus santos, ya a través de las imágenes de Cristo y la Virgen María. Esas narraciones eran consideradas tan históricas como las hazañas guerreras de los reyes y los nobles; la distinción que nosotros hacemos entre literatura ficcional e historia "verdadera" no existía ([en proceso]: s. p.).

Para los fines de este estudio, me adhiero a la idea sostenida aquí por Rubial de que el milagro en sí es obra de la divinidad y favorece a los seres humanos sólo mediante

${ }^{13}$ En el artículo "Nuestra Provincia", publicado en la página web de la Orden de la Merced de la Provincia de México, se hace referencia a "las fundaciones de los conventos mercedarios en toda la geografía de la Nueva España: en 1598 se funda el convento de Puebla, en 1601 el de Oaxaca, en 1604 el de Valladolid, hoy Morelia, en 1607 el de la Inmaculada Concepción de Tacuba y el de Colima, en 1613 los de Veracruz y Atlixco [...] En 1626 se funda el Convento de Belén y de su Colegio de San Pedro Pascual, extra muros de la Ciudad de México, en 1628 el convento de San Luis Potosí, en 1629 el de Guadalajara" (s. p.).

${ }^{14}$ En su estudio sobre dicha literatura, Rubial incluye tanto la hagiográfica como la que él denomina "hierofánica": "Utilizamos el término 'literatura hierofánica' (y no la tradicional denominación de 'aparicionista') para darle nombre a este conjunto de impresos que reúnen características similares entre sí, pues se trata de narraciones que describen manifestaciones de lo sagrado, las cuales muy a menudo no se referían propiamente a una aparición” ([en proceso]: s. p.). 
el santo (a esto volveré más adelante). ${ }^{15}$ La "literatura de prodigios" tenía, además, un claro objetivo didáctico-moralizante: mediante los relatos prodigiosos se proponen ejemplos a seguir para el público creyente, a pesar de la aparente inverosimilitud de lo relatado. De acuerdo con Rubial:

Para hacerse valiosos y legitimar su veracidad, los relatos de prodigios debían sujetarse a modelos sacralizados y ejemplares en los que virtudes y milagros se repetían y eran intercambiables entre un santo y otro, sin tener en cuenta criterios de realidad demostrable. Lo importante era la verdad moral, el deber ser, y su valor estaba supeditado al uso que se le podía dar como guía para transitar por el mundo en camino hacia la salvación eterna ([en proceso]: s. p.).

En el certamen, se pone claramente de relieve la intención de confirmar la santidad y la ejemplaridad de Nolasco al mostrar que fue digno de recibir favores celestiales, mediante los que él mismo también hizo grandes obras. En el manuscrito del Libro segundo y en el cartel de la convocatoria al certamen se reiteran, implícitamente, estas ideas a través de ciertos términos, de los cuales, en el presente estudio, examinaré: milagro, prodigio, maravilla, portento y favor (así como sus raíces latinas en el caso del concurso de epigrama). Comenzaré con algunas observaciones sobre los términos y su uso en el periodo histórico al que corresponde el certamen. De acuerdo con la primera acepción de su significado en el Diccionario de Autoridades, el milagro es obrado específicamente por la divinidad: "Obra divina, superior a las fuerzas y facultad de toda criatura, contra el orden natural. Sale del latino miraculum, que significa lo mismo"; mientras que el prodigio implica (también en su primera acepción) un "suceso extraño que excede a los límites regulares de la naturaleza. Latín prodigium". Ambos, pues, de-

${ }^{15}$ La polémica respecto a si los santos mismos pueden o no obrar milagros data desde el medioevo y se nutre de numerosas tradiciones hagiográficas y literarias; sin embargo, considerar las ramificaciones de dicha polémica sobrepasa los propósitos del presente texto. Al respecto, sólo citaré algunas observaciones puntuales que hace Manuel Pérez en su estudio Los cuentos del historiador, donde explica que Tomás de Aquino afirmaba "que es Dios el único que puede hacer milagros en virtud de que es el único ser increado" (2012: 93); pero el historiador carmelita novohispano fray Agustín de la Madre de Dios, por ejemplo, amplió este concepto, escribiendo que: "Aunque es verdad que Dios solo es el autor de las obras milagrosas, llegando con su brazo omnipotente a todo lo que es prodigio, también lo es que sus siervos hacen y han hecho milagros, o valiéndose Dios del ministerio suyo para hacerlos o intercediendo con él para que los ejecute" (citado por Pérez, 2012: 93). Pérez también apunta: "no debe olvidarse que la capacidad de hacer milagros fue adjudicada a los santos desde un principio", pero agrega que, "en la mayoría de los casos, el milagro hagiográfico sólo se proponía para suscitar la alabanza al poder de Dios" (2012: 99). Para mayor información sobre la clasificación de los milagros y su carácter histórico, así como acerca de la distinción entre "milagro hagiográfico" y "milagro literario", véase Lacarra; Montoya; y Pérez, 2008. 
safían los límites de lo natural, pero el milagro es, además, necesariamente divino; sin embargo, el uso de prodigio también se registra en Autoridades como sinónimo de milagro, en su tercera definición: "prodigio. Se toma asimismo por milagro". De manera curiosa, en el manuscrito del certamen y en la convocatoria, el término prodigio nunca se aplica a los sucesos denominados como milagrosos ni viceversa. También, cabe señalar que fray Juan de Alavés es el único escritor que utiliza los términos "milagro" /"milagroso" (los cuales no aparecen en la poesía premiada); a esto aludiré más adelante.

Los términos maravilla y maravilloso(a) se relacionan estrechamente con el milagro, aunque no de manera sinónima. Como explica Manuel Pérez, desde la definición que da Alfonso X del milagro, ${ }^{16}$ se "ofrece[n] dos elementos para su caracterización: que es obra de Dios y que es maravillosa [...] En la Edad Media [...] los milagros se singularizaron frente a las otras maravillas de distinto signo que poblaban la imaginación y la realidad medievales; es decir, todo milagro era en este sentido una maravilla, aunque no toda maravilla era un milagro" (2008: 51). En el certamen, sin embargo - como es el caso de prodigio-, maravilla/maravilloso(a) no se emplean para referirse a los sucesos hagiográficos que Alavés califica como milagrosos. En Autoridades, la maravilla es un "Suceso extraordinario que causa admiración y pasmo. Covarrubias dice sale del verbo latino miror, aris. Latín mirum, $i$; res mira; miraculum”. En el Libro segundo, su uso se relaciona con dos tradiciones en la vida de Nolasco y, asimismo, se utiliza en la denominación de la Ciudad de México como "octava maravilla". ${ }^{17}$

Portento, por su parte, es "cualquier singularidad o grandeza que por su extrañeza o novedad causa admiración o terror, dentro de los límites de la naturaleza. Sale del latino portentum" (Autoridades). En el caso de sólo uno de los episodios hagiográficos que prestan sus temas al concurso, Alavés emplea tanto el término milagro como portento; según se verá, el cambio del primero al segundo entre la redacción del cartel, por un lado, y la del Libro segundo, por otro, puede ser indicio de una especie de reconsideración al respecto por parte del secretario. Por último, las acepciones de favor más pertinentes en cuanto al uso del término en el manuscrito del certamen son "Ayuda, socorro, patrocinio y amparo. Es voz latina favor, -oris" y "honra, beneficio o gracia que se concede a alguno. Latín honor, gratia" (Autoridades). En el manuscrito, el término favor se utiliza en referencia a los acontecimientos que también se denominan como milagro o prodigio.

\footnotetext{
${ }^{16}$ En esta definición, milagro "quiere decir como obra de Dios maravillosa que es sobre la natura usada de cada día, y por ende acaece pocas veces" (Alfonso X: 190).

${ }^{17}$ Aunque no me detendré en este uso de maravilla, pues no está relacionado con el santo, cito las dos instancias de su empleo: en las liras de Diego Ramírez de Villegas, llama a la ciudad "esta del mundo octava maravilla" y realiza una ingeniosa comparación entre la urbe y el pavorreal (véase Alavés, 2019 [en prensa]: f. 27v); y en las liras de Pedro Marmolejo Machuca, se lee que, en una época anterior (antes de la llegada de las inundaciones, en este caso), la ciudad "pudo, como estaba/ ser, de las siete, maravilla octava" (2019 [en prensa]: f. 29v).
} 
Cada una de las temáticas en las que se centran los primeros siete concursos poéticos se describen con, por lo menos, uno de estos cinco términos, y algunas con más de uno; de ese modo, reitero, se remarcan ideas subyacentes en todo el manuscrito: el hecho de que Nolasco fue favorecido por Dios (y también por la Virgen María) y que, por extensión, fue digno del reconocimiento de su santidad mediante su canonización. Ahora bien, daré ejemplos de su uso para entender las tendencias en el manuscrito en cuanto al empleo de los cinco conceptos. En lugar de, simplemente, examinar los concursos en el orden en que aparecen en el certamen, consideraré primero los que tratan sobre sucesos que el secretario del concurso, Juan de Alavés, llama "milagros" / "milagrosos" - epigrama, octavas y glosa-; después, se verá cómo algunos poetas ganadores en dichos certámenes denominan esos mismos sucesos; y de ahí partiré para hacer conexiones con la terminología empleada para referirse a las temáticas en las que se basan los concursos de décimas, soneto, liras y canciones.

Respecto al concurso de epigrama, parece no haber mayor discusión: para fray Juan de Alavés, la formación de un panal en la mano derecha del niño Nolasco fue un milagro. En el cartel se especifica, para este concurso, que "La Luna, presidente del primer cielo $[. .$.$] pide un ingenioso y agudo epigrama que no pase la raya de cuatro$ dísticos compendiosos en que, con relevante poesía, se pondere aquel suceso milagroso cuando, estando nuestro santo en la cuna, en su mano derecha formaron las abejas un panal, significativo pronóstico de la dulzura y suavidad de este divino Aristeo" (¿1632?: 1). ${ }^{18}$ En la introducción a este certamen en el manuscrito, Alavés escribe: "La Luna, como madre del rocío, pidió un agudo epigrama que no llegase a cinco dísticos ${ }^{19}$ en que se ponderase la milagrosa fábrica del panal que formaron las abejas en la palma de Nolasco" (1633b: f. 4v). Ninguno de los poetas ganadores usa el término miraculum ni prodigio, pero sí hay una instancia de honor ("Caelestem sponsum geminato imitaris honore:/ dextra favos, sed lac pulchra labella rigant”, Alavés, 1633b: f. 7r ${ }^{20}$ y una de gratia en un epigrama en el que se junta a Moisés, a Elías y a Nolasco como hombres "preclaros" ("Sedula designat fati praesaga futuri/ gratia praeclaros, ingenuosque viros", Alavés, 1633b: f. $7 \mathrm{v}) \cdot{ }^{21}$

${ }^{18}$ Aristeo: hijo de Cirene y Apolo, diestro en el arte de la apicultura (Grimal: 52); de ahí la comparación entre él y Nolasco en este certamen, donde el tema es el panal que hicieron las abejas en la mano del niño Nolasco.

${ }^{19}$ que no llegase a cinco dísticos: es decir, que no pase de cuatro dísticos, como se pidió en la convocatoria.

20 "Imitas al esposo celeste con honor duplicado: la diestra riega panales, pero los hermosos labiecitos riegan leche" (las traducciones del latín son mías). Aquí se alude a la imitación de Jesucristo por parte de Nolasco; después comentaré la relación que se establece entre los dos en otros poemas.

21 "La gracia activa, presagiadora del futuro destino, señala a los varones preclaros y nobles". 
Hay, además, en otro epigrama ganador, un uso de portentum. Se establece una relación, basada en los elementos del enjambre de abejas, el panal y la miel, entre Nolasco y Sansón; éste mató un león joven y días después vio, en el cadáver del animal, un enjambre de abejas y miel (Jue 14: 6-9). El enigma que propuso Sansón a raíz del suceso fue: "del que come salió lo que se come, y del fuerte la dulzura" (Jue 14:14). El epigrama ganador del quinto lugar en este concurso, escrito por Cristóbal Bernardo de la Plaza, "secretario de la Real Universidad de México", evoca precisamente el enigma de Sansón en relación con Nolasco:

Ore leonino putridoque cadavere Sanson

vidit apes proprios instituisse favos.

Hinc fuit aenigma, ex forti dulcedo; puelli

Nolasci manibus iam nova signa vides

En circumvolitat dextram super oreque fingit

agmen apum roseos melle liquante favos.

Quid portenta serant? Si quaeras causa patescit

fortis Marte puer, dulcis in arte puer (Alavés, 1633b: f. 6v). ${ }^{22}$

En sí, la comparación de Nolasco con Sansón, hecha por el autor del epigrama, puede interpretarse como una alusión a la grandeza del santo homenajeado en el certamen; existe una larga tradición, por ejemplo, de la interpretación de Sansón como una especie de prefiguración crística. Al respecto, Josey Bridges Snyder explica:

For many Christian interpreters, the demonization of Delilah corresponds to the lifting up of Samson as a saint. These interpreters build their characterization of Samson on a New Testament passage that lists Samson as a man of great faith alongside men like David, Samuel, and the prophets (Heb. 11:32). However, they carry their praise even higher than the author of Hebrews by claiming Samson as a figure of Christ. Caesarius of Arles (ca. 470-543), for example, sees Christ prefigured in Samson's death. When he describes Samson's final act in the Philistine temple, Caesarius remarks "Notice here an

22 "Sansón vio que las abejas construían sus propios panales en las fauces del león y en su cadáver pútrido. De aquí fue el enigma: la dulzura desde el fuerte [león]; en las manos del niño Nolasco ahora ves signos nuevos. Mira: un enjambre de abejas revolotea alrededor de su diestra y sobre su boca dibuja panales rosados de miel líquida. ¿Qué sembrarían los portentos? Si lo preguntas, la causa se descubre: un niño fuerte por Marte, un niño dulce en el arte". Hay otras dos referencias a Sansón en el certamen: en las décimas de fray Miguel de Linares, ganadoras del tercer lugar en dicho concurso, él llama a Nolasco "en la iglesia otro Sansón/ no para morir con ellos/ sino con paz atraellos/ a la verdadera unión" (1633b: f. 10v); y en el soneto "estrambotado" de Hernando Ceballos (un "estrambote" son "versos o copla añadida al fin de alguna composición poética, especialmente en los sonetos, para mayor expresión, lucimiento y gracejo", Dicc. Aut.), se alude a Nolasco como "fuerte Sansón, socorro de cristianos/ presos de sarracenos y africanos" (1633b: 16v). 
image of the cross. Samson extends his hands spread out to the two columns as to the two beams of the cross" (Sermon 118.6) (139). ${ }^{23}$

Del mismo modo en que resultó extraordinaria la presencia de un enjambre de abejas en el cadáver del león muerto por Sansón, lo fue el panal formado por las abejas en la mano del niño Nolasco; de manera similar, tal y como Sansón representó, para algunos intérpretes cristianos, una "figura de Cristo", también así Nolasco, aunque no por prefigurarlo, sino por imitarlo. De hecho, se alude al papel de este último como "redentor segundo" después de Cristo (Alavés, 1633b: f. 12v) y a otros aspectos de su conexión con Jesucristo en otros concursos del certamen, sobre lo cual comentaré más adelante.

El siguiente concurso, cuya temática es considerada por Alavés como "milagrosa", es el cuarto, el de octavas. Escribe en la convocatoria:

El sol [...] quiere que en seis octavas castellanas se realce aquel milagro estupendo obrado por Nolasco cuando, a vista de la morisma, echado por los moros de Argel, en un barco viejo, roto, sin vela ni remo, sin bastimento ni vitualla, haciendo mástil de su cuerpo y vela de su blanca capa, se engolfó en el tormentoso mar y mal enojado elemento, y le pasó con seguridad hasta desembarcar sin detrimento alguno en la playa de Valencia, en menos de diez horas, donde los circunstantes preguntaban: Quis est hic cui venti et mare obediunt? (¿1632?: 1). ${ }^{24}$

Alavés afirma que este "milagro" fue "obrado por Nolasco", y de ese modo insinúa que el propio santo posee habilidades sobrenaturales, lo cual, por su parte, podría confirmar de nuevo el favorecimiento que gozó de las fuerzas divinas. Pero si se piensa en las implicaciones del concepto milagro y en la consideración de que se trata de una obra divina, entonces, en teoría, no sería, per se, obra del propio santo, aunque él podría haber sido el receptor del milagro y actuar como intercesor entre la divinidad y otros seres humanos. ${ }^{25} \mathrm{Al}$ igual que ocurrió en el caso del primer concurso, el secre-

23 "Para muchos intérpretes cristianos, la demonización de Dalila corresponde a la exaltación de Sansón como santo. Estos intérpretes basan su caracterización de Sansón en un pasaje del Nuevo Testamento que considera a Sansón como un hombre de gran fe junto con hombres como David, Samuel y los profetas (Heb. 11:32). No obstante, elevan sus alabanzas a un grado todavía más alto que el autor de [la epístola a los] Hebreos al sostener que Sansón es una figura de Cristo. Cesáreo de Arlés (ca. 470-543), por ejemplo, ve a Cristo prefigurado en la muerte de Sansón. Al describir el último acto de Sansón en el templo filisteo, Cesáreo afirma: 'Nótese aquí una imagen de la cruz. Sansón extiende sus manos a las dos columnas cual si fueran las vigas de la cruz"'.

24 “Quién es éste a quien los vientos y el mar obedecen?” En el Evangelio según Marcos, ésta es la pregunta que hicieron los discípulos acerca de Cristo cuando calmó una tempestad que les sobrevino mientras se encontraban en un barco en el mar de Galilea (Mc 4:41).

${ }^{25}$ Véase la nota 15 a este respecto. 
tario es el único que usa el término "milagro" en relación con el cruce de Nolasco por el mar Mediterráneo, y sólo lo emplea en el cartel. Algunos de los poetas ganadores se refieren al suceso como "portento", por lo que podría suponerse que Alavés siguió su ejemplo al adoptar mejor este término - de una u otra forma más modesto- en la introducción al certamen en el Libro segundo - ahí, apunta "aquel portento raro de haber pasado nuestro glorioso santo las aguas del mar en un barco desmenuzado" (1633b: f. 16v)-, pues, para cuando escribió dicho apartado, él ya habría conocido los poemas entregados al concurso. ${ }^{26}$ Jerónimo de Alzate, ganador del primer lugar en el concurso de octavas, concluye su poema con estos versos: "Ilega a Valencia, pues, donde repite/ el vulgo, '¿quién es éste?', él se responda:/ 'éste es Nolasco, en santidad portento,/ a quien respeta el mar y aplaude el viento"” (1633b: f. 18r). Antonio Lobo, ganador del segundo lugar, emplea tanto portento como maravilla: “ $\mathrm{iOh}$, Nolasco, tu ardiente celo puro/ sólo obrara tamaña maravilla!'/ dijo el puerto y, por salva a tal portento,/ ‘Quién es éste, que rinde al mar y al viento?’” (1633b: f. 18v).

En el séptimo certamen, el de glosa, es de nuevo el propio Alavés quien usa el concepto de "milagro", pero no lo atribuye directamente al santo; escribe, en el cartel, que Saturno "pide una glosa española en que se trate de la milagrosa fundación de la Orden de Nuestra Señora de la Merced, Redención de Cautivos" (¿1632?: 1). Aquí, se puede interpretar que tendría justificación llamar la fundación "milagrosa" si se entiende que resultó de la intercesión de María en nombre de Dios al pedirle a Nolasco que estableciera la orden, así como del hecho de que Jaime I y san Raimundo de Peñafort apoyaron la iniciativa del santo, ya que "habían tenido unas visiones parecidas" (García: 35). Aun así, de nuevo, Alavés es el único que emplea "milagrosa" con respecto a la fundación y, otra vez, cambia el término por otro en la introducción al concurso en el Libro segundo, optando, en esta ocasión, por "maravillosa": "Saturno [...] pidió una glosa en que se tratase de la maravillosa fundación de nuestra sagrada Orden de Nuestra Señora de la Merced que encargó Dios a nuestro glorioso padre san Pedro Nolasco" (1633b: f. 30r). El dominico fray Felipe de Sámano prefiere llamarla simplemente un "favor": "Por imitar la elección/ de Cristo, la Virgen piedra/ os hace de su religión,/ [...] tal favor agradeced, Nolasco

\footnotetext{
${ }^{26}$ Irving Leonard explica el papel que tenía el secretario en la evaluación de los poemas entregados en los certámenes novohispanos en general: "después de un aventamiento preliminar de la paja más obvia, llevaba el secretario [las] contribuciones [poéticas] a una reunión de los jueces en la casa del mayordomo [patrocinador del concurso...]. Sin duda la sesión se prolongaba mientras que los jueces iban revisando [...] una vasta colección de romances, glosas, décimas, quintillas, sextetos, sonetos, octavas, sáficos, canciones, epigramas y anagramas, tanto en latín como en español [...] A pesar de las cerniduras preliminares del secretario, la tarea era agotadora" (205).
} 
santo, pues vos" (1633b: f. 32v). ${ }^{27}$ Así, se enfatiza la relación entre la Virgen y el santo, sobre la que hay también otras referencias en el certamen y a las cuales aludiré después. Por su parte, Andrés Lagarto, ganador del tercer lugar en el concurso de glosa, hace referencia a una conexión entre Nolasco y Dios, basada en que aquél es "segundo redentor" después de Éste:

Que haber redentores dos
sólo es dado a vos y a Dios;
y así no dude ya el mundo
quién es redentor segundo,
Nolasco santo, pues vos.
Si otro Dios haber pudiera,
vuestro fuera este favor,
que Dios, que os puso en esfera
de sin igual redentor,
su divinidad os diera (1633b: f. $31 \mathrm{v})$.

El concepto de Nolasco como "redentor segundo" también aparece en el concurso de décimas. Sin embargo, como una especie de paréntesis, quisiera hacer un breve comentario sobre una cuestión a la que ya he aludido: sólo se encuentra la terminología milagro /milagroso empleada por el propio Alavés al referirse a las tradiciones relacionadas con Nolasco. Podría especular que esto se debe, simplemente, a que él es el único mercedario cuyas palabras se leen en el Libro segundo, así como en el cartel de la convocatoria (con la posible excepción del anónimo padre de Teología, cuyo epigrama fue premiado "en honra" y del que ya he hablado). En otras palabras, quizá el secretario quería enfatizar la calidad milagrosa de las obras relacionadas con el santo fundador de su orden, sencillamente, porque él, como mercedario, sentía un gran afecto hacia Nolasco, mayor que el de los participantes de otras órdenes o laicos. No obstante, cabría advertir que tampoco se debe leer demasiado entre líneas con respecto al uso del término milagro en la pluma de Alavés, ya que también lo emplea para hacer una broma acerca de la pobreza de los poetas, tema recurrente en sus intervenciones en el Libro segundo. En la letra que escribe para el ganador del segundo lugar en el concurso de canción, Juan de Santoyo, afirma: "Jarra de plata os envía/ Apolo: estimadlo vos,/ porque es milagro de Dios/ juntar plata y poesía". ${ }^{28}$

${ }^{27}$ Los versos que se deben glosar en los poemas para este concurso son: "Nolasco santo, pues vos/ La Merced fundáis, podéis/ decir que con lo que hacéis/ hacéis mercedes de Dios" (1633b: f. 30r). Alavés considera que se trata de un texto "dificilísimo", quizá debido a los encabalgamientos y a la rima en palabras agudas.

${ }^{28}$ Otro ejemplo de la tendencia de Alavés a hacer bromas sobre la pobreza de los poetas está en sus palabras preliminares en el f. 1r del Libro segundo: "a siete de enero [...] ya era tiempo 
Ahora bien, sobre el concurso de décimas, Alavés se refiere en el cartel a la "maravillosa visión" que tuvo Nolasco en un sueño, en la que dos ancianos - que se sugiere en la convocatoria fueron san Pedro y san Pablo - le enseñaron una oliva y le encargaron su cuidado contra los etíopes que intentaban talarla. Antonio Álvarez de Ocampo retoma, en sus décimas, esta denominación de "maravillosa visión” y considera que el suceso fue un "prodigio":

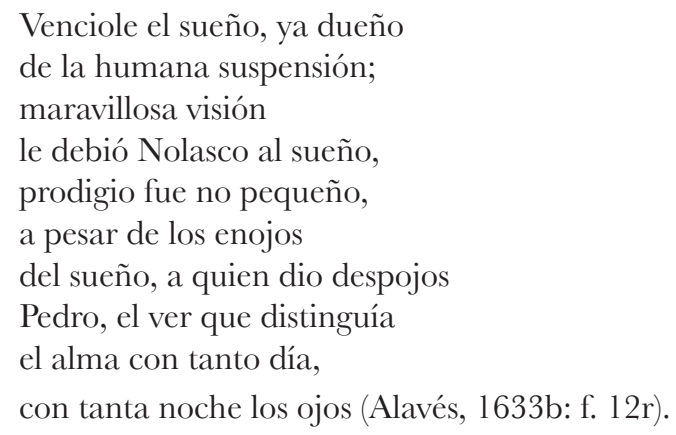

En las décimas del franciscano fray Juan de Echavarría, se establece una correspondencia entre Cristo y Nolasco, basada, en parte, en el concepto de Nolasco como "redentor segundo":
A Cristo imitar queréis con afectos compasivos en los ejemplos más vivos, pues para cobrar renombre al escuadrón dais por nombre la redención de cautivos. $[\ldots]$ Nolasco, dais a entender que sois redentor segundo (1633b: f. 12v).

Asimismo, el presbítero Lorenzo Ortiz también relaciona a Nolasco con Cristo y estima que la visión fue un "favor extraordinario":

$$
\begin{aligned}
& \text { Bajan de etéreas regiones } \\
& \text { con júbilos singulares } \\
& \text { los apóstoles a pares, }{ }^{29} \\
& \text { los ángeles a millones. }
\end{aligned}
$$

de despenar a los poetas que, como pobres, vivían de esperanzas, y deseaban, con ahínco de tales, el buen logro de ellas".

${ }^{29}$ apóstoles a pares: san Pedro y san Pablo. 


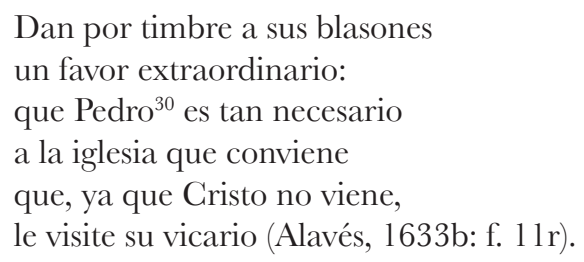

La conexión entre el santo mercedario y Jesucristo constituye un tópico relativamente frecuente en las tradiciones en torno a Nolasco, y se puede vincular también con la relación entre éste y la Virgen María, la cual cuenta con numerosas referencias en el tercer concurso, el de soneto. Dicho concurso tiene como tema el "favor" — término empleado tanto en la convocatoria ("extraordinarios favores", ¿1632?: 1) y en la introducción en prosa de Alavés a este concurso ("favor extraordinario", 1633b: f. 13v) como en la poesía ganadora - que le hizo la Virgen María a Nolasco al asistir por él en el coro de Barcelona. Manuel Mariano Ribera explica en qué consiste la tradición:

cuando, habiéndose olvidado el campanero de tocar a maitines de aquella noche, fue el santo hacia el coro, y reparándole lleno de admirables luces, llegó a la puerta y vio a María con sus ángeles vestidos del hábito mercenario, ${ }^{31}$ que, cantándolos, se hizo favor al santo que prosiguiese con ellos. Dícelo el antiquísimo público y auténtico instrumento que en los Idus de Mayo 1260 hizo Pedro de Bages, notario público de Barcelona (67).

Los poetas del certamen de 1633 aluden, en sus composiciones, a ese amparo que tenía Nolasco por parte de la Virgen. El mismo Juan de Echavarría, quien participó en el concurso de décimas, se dirige a Nolasco en su soneto y escribe: "gozad vos el favor" (1633b: f. 14v); Diego de Ortega se refiere a "La madre santa que, de gloria llena,/ a Nolasco corona de favores" (1633b: f. 16r); y fray Francisco de Villalobos apunta: "Cesen ya los suspiros, y responda,/ Pedro, al favor de la divina Reina,/ amor vertido en perlas de alegría” (1633b: f. 15v). Manuel de Olmedo no emplea explícitamente el término favor, pero insinúa, en sus tercetos, que el hecho de asistir María por Nolasco en el coro es una muestra del especial cariño que la Virgen le tenía al santo:

¿Esto no es mucho? ¿Que de Dios la madre al coro asiste, de Nolasco al lado,

\footnotetext{
${ }^{30}$ Pedro: aquí, Nolasco, no el apóstol.

${ }^{31}$ En textos de la época, es frecuente el uso del término "mercenario" para referirse al "mercedario"; véanse, por ejemplo, los villancicos de sor Juana Inés de la Cruz a Nolasco: "De sentir el modo es vario,/ pues al mirar su fervor,/ todos dicen que es pastor,/ pero yo, que es mercenario" (29).
} 
y el oficio comienza, hebdomadaria? ${ }^{32}$

¿Qué es esto, venerable y santo padre?

Vos sois de María prebendado, ${ }^{33}$

o ella debe de ser vuestra vicaria.

El privilegio del que goza Nolasco en su relación con María, concepto mediante el que se reitera claramente que era merecedor de la gracia divina, se suma a otros testimonios presentes en la hagiografía de este santo sobre el amor de la Virgen María hacia él. Éstos incluyen, como ya se ha visto, la petición que ella le hizo de fundar la Orden de la Merced, así como la lactación de san Pedro por María y la hermandad de Nolasco con Cristo. ${ }^{34}$ Louis Cardaillac explica que

san Bernardo de Claraval, san Pedro Nolasco, santo Domingo, san Cayetano, san Agustín, san Vicente son los beneficiarios más conocidos de esta lactación. En muchos casos los artistas encuentran su inspiración en los relatos de las vidas milagrosas de los santos que también se inspiraban del pensamiento medieval [...] Todos los santos que acabamos de enumerar se caracterizan por su gran devoción a la Virgen que los premia haciendo de ellos "unos hermanos de leche de Cristo". Subir a esta categoría es merecer ser considerado como otro Cristo, perder los accidentes de su naturaleza humana, como la edad, para recuperar el estado de gracia del niño. Aquello merece a uno el acceso al paraíso, es decir

${ }^{32}$ Concuerdo con Martha Lilia Tenorio (365) en que hebdomadaria está en femenino porque se refiere a María. Hebdomadario: "lo mismo que semanero en las comunidades eclesiásticas" (Dicc. Aut.). Semanero: "La persona que está ejerciendo algún empleo por el término de una semana, en que entra por turno" (Dicc. Aut.). Oficio: "se llama el rezo que tienen obligación a decir todos los días los eclesiásticos, en el Coro u otra parte, compuesto de maitines, laudes, prima, tercia, sexta, nona, vísperas y completas" (Dicc. Aut.). Aut.).

${ }^{33}$ prebendado: "dignidad, canónigo o racionero de las iglesias, catedrales y colegiales" (Dicc.

${ }^{34}$ Cardaillac se refiere al concepto de la hermandad del santo mercedario con Jesucristo en su descripción de La lactancia de san Pedro Nolasco de Ignacio Chacón (1663), al señalar que, en el cuadro, los dos son amamantados al mismo tiempo por María: "el lienzo llamado Lactancia de san Pedro Nolasco [es] obra de Ignacio Chacón de 1663 y [...] se encuentra en el monasterio de la Merced en el Cuzco, Perú. Es el ejemplo perfecto que ilustra el comentario que presentamos más arriba. La Virgen amamanta en su pecho derecho a un anciano barbudo que es el propio Pedro Nolasco y en su pecho izquierdo, al niño Jesús. Tiene a los dos abrazados con un gesto de gran ternura. Mantiene al niño Jesús sentado en su pierna izquierda, mientras el santo, arrodillado, se apoya en la pierna derecha para poder beber la leche de María" (Cardaillac: $\S 74)$. En sus villancicos a san Pedro Nolasco (1677), sor Juana se refiere a la hermandad de los dos, implícita en que ambos son hijos de María: "Aunque cualquier santo puede/ ser hijo de María hijo amado,/ en título tan honrado/ a todos Nolasco excede:/ pues a él se le concede/ como heredero, este día,/ por ser hïo de María./ La reina de la belleza/ a los dos da vestidura:/ a uno, de su carne pura,/ y al otro, de su pureza;/ Pedro goza tal grandeza/ que a Cristo solo venía,/ por ser hïo de María" (29; las cursivas son mías). 
la intimidad con la Virgen y el niño Jesús. Ya están todos bajo el amparo de la Virgen, la mujer buena del Apocalipsis (§69-70).

Queda claro, tanto en las tradiciones hagiográficas en torno a Nolasco como en el concurso de soneto del certamen, que, con la ejemplaridad de su vida, sus obras y su devoción a la causa de la redención de cautivos, él es digno de ocupar un lugar privilegiado entre los santos y de recibir favores, en este caso, de la Virgen.

El concepto de favor también opera en el sexto concurso poético, el de liras, pero aquí no se trata de favores que recibe Nolasco, sino del que se le pide al propio santo de interceder por los habitantes de la ciudad y por la ciudad misma para bajar las aguas que aún los afligían a raíz de las inundaciones. Para este concurso, Júpiter solicitó liras "bien templadas, en que se pida a nuestro glorioso padre san Pedro Nolasco mire con ojos compasivos a esta nobilísima ciudad con la presente inundación atribulada, y pida a nuestro Señor que recoja las aguas atrevidas que le aguan sus antiguas glorias y placeres" (1633b: f. 26r). Alavés no utiliza, en la convocatoria del certamen ni en la introducción al sexto concurso, ninguno de los términos que se han examinando; sólo en la composición del bachiller Alonso de Mena se emplea el concepto de favor, con lo cual se insinúa que Nolasco es, en efecto, capaz de responder a dicha petición. Refiriéndose a la misma ciudad, el poeta afirma:

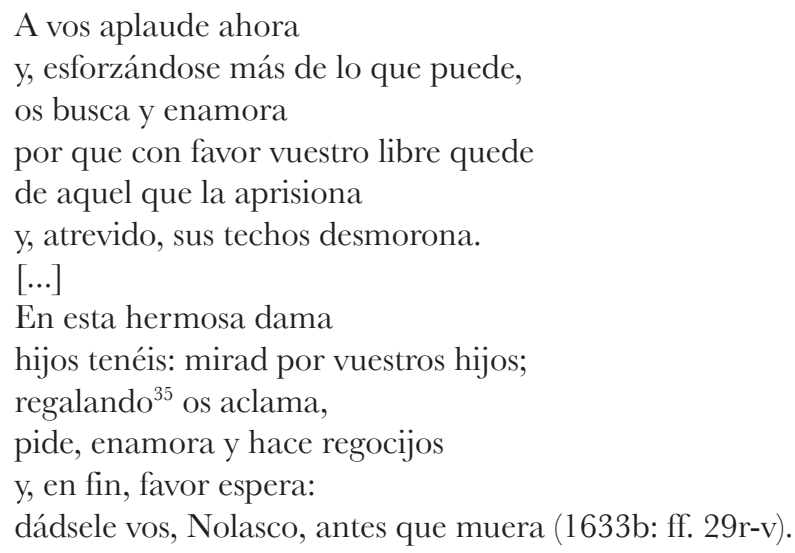

Éste es el único concurso estudiado en el presente artículo que no se basa en un tema hagiográfico o histórico relacionado con la vida de Nolasco; aquí, se convierte al santo en un protagonista actual, es decir, del momento histórico al que corresponde el certamen. Con esto se revalida tanto el poder de la figura de Nolasco como su

\footnotetext{
35 regalando: regalar "se toma tambien por halagar, acariciar, o hacer expresiones de afecto y benevolencia" (Dicc. Aut.).
} 
vigencia y relevancia para la sociedad que lo homenajea en las fiestas de 1633 . Al igual que María puede obrar favores para auxiliar a Nolasco, éste, por su parte, tiene la posibilidad de conceder un favor a la Ciudad de México, intercediendo por ella y por sus habitantes, con el fin de ayudarlos a superar las graves consecuencias de la catástrofe natural que, como ya se dijo, obstaculizó durante varios años la celebración por la canonización del santo. Resulta pertinente, entonces, que se aluda al suceso climatológico en el certamen, pues, al atribuirle a Nolasco, en este concurso de liras en particular, la capacidad de mejorar la suerte de la ciudad que tanto amor le brinda en los festejos de 1633, representa una muestra simbólica de la fe de los mexicanos en el fundador de la Orden de la Merced.

En el quinto concurso, el de canción, la temática es propiamente histórica: la participación del santo en la reconquista de Sevilla, emprendida por el rey Fernando III de Castilla. De manera conveniente, Marte, dios de la guerra, convoca este concurso. En el cartel, Alavés escribe:

Marte, presidente del quinto cielo [...] demanda una grave canción real de seis estancias castellanas con su remate en que, con delicada pluma y primoroso pincel, los ingeniosos poetas mexicanos [...] describan el cerco y toma a [sic] de la populosa ciudad de Sevilla, en que se halló presente san Pedro Nolasco con toda la caballería primitiva de su orden, y entró triunfando al lado del señor rey don Fernando, y fundó el convento magnífico que allí tiene esta sagrada religión (¿1632?: 1).

Según Diego Ortiz de Zúñiga, Nolasco "profetizó la victoria que tuvo el santo rey don Fernando, ganando esta ciudad de Sevilla. Asistió al lado del santo rey el tiempo que la conquistó por mandado de su majestad, predicó en sus ejércitos y convirtió muchas almas [...] Rescató a tres mil setecientos y setenta cautivos; hizo ejército de todos para que ayudasen al santo rey en la conquista" (381).

Es importante notar que, en el manuscrito del Libro segundo, sólo se incluyen dos canciones premiadas; falta la de Juan de Santoyo, ganador del segundo lugar (se dejó un espacio en blanco, al parecer para incluirla después, lo cual no se hizo), así como otras que se premiaron "en honra". Alavés apunta: "Otras canciones parecieron en juicio dignas de premio (a no haberse ya acabado), en particular, una de un padre de la Compañía de Jesús sin nombre; otra, de Bartolomé de Góngora; y otra, del padre fray Miguel de Carvajal, agustino" (1633b: 26r). Debido a la ausencia de dichas canciones, obviamente no se puede saber con qué términos se refirieron a este acontecimiento histórico los demás poetas; lo que sí se puede observar es que, en las dos canciones que se reproducen, hay un solo uso de uno de los cinco términos cuya presencia he ido examinado: en este caso, "prodigio". En la canción de Francisco Bramón, ganador del primer lugar en el concurso y uno de los pocos poetas participantes en el certamen que era conocido en vida por sus habilidades poéticas (según José Ma- 
riano Beristáin de Souza, "uno de los buenos poetas de la América", que escribió Los sirgueros de la Virgen sin pecado original, publicado en 1620 [211]), se emplea el término "prodigio", pero no directamente relacionado con la intervención de Nolasco en la reconquista de Sevilla, sino con el hecho de ésta en sí:

\author{
que el nuevo patriarca \\ al lado triunfa de Fernando invicto, \\ después del gran conflicto \\ por las plazas rendidas de Sevilla, \\ llevando su cuadrilla \\ las sienes coronadas que, por vellas, \\ aguija el sol y corren las estrellas. \\ Vencida, Jericó, las puertas francas, ${ }^{36}$ \\ rotos sus muros, dio, ${ }^{37}$ por que gloriosa \\ el Arca del Señor triunfos prosiga, \\ prodigio del poder de la preciosa \\ Arca divina que, con pieles blancas, \\ al bárbaro furor valiente hostiga (1633b: f. 22v).
}

La reconquista de Sevilla es "prodigio del poder" del cristianismo debido al triunfo de las tropas del rey Fernando. Es posible que no se encuentre un mayor uso de los términos cuyo empleo en el certamen se ha ido estudiando por tratarse de un suceso histórico tangible, y no de una tradición únicamente hagiográfica; sin embargo, también puede deberse a que sólo hay dos canciones en el manuscrito, mientras que en los otros concursos se reproduce un número mayor de composiciones (hasta 10 en el de epigrama).

El certamen mexicano de 1633 en honor a san Pedro Nolasco ofrece múltiples evidencias de la convicción que tenían los poetas participantes respecto a la excepcionalidad y ejemplaridad del santo, a la trascendencia de sus obras y de su labor como redentor de cautivos, y a la gran repercusión de la fundación de la Orden de la Merced. Los poemas que reflejan dicha convicción, mediante el uso de la terminología examinada aquí, representan una prueba del prestigio que gozaban tanto la figura de Nolasco como la orden en México durante el siglo XVII; esto, reitero, queda claro, en parte, porque los ganadores en los concursos no pertenecían a esa orden y, aun así, participaron con entusiasmo en el certamen, luciendo sus habilidades poéticas para engrandecer el homenaje realizado por los mercedarios mexicanos. Y, por supuesto, también había, además del "premio" que significaba el reconocimiento público de la aptitud de los poetas, otro incentivo para que éstos se esmeraran en rendir homenaje al santo de la

\footnotetext{
${ }^{36}$ francas: "Franco. Vale tambien desembarazado, libre, y sin impedimento alguno" (Dicc. Aut.); es decir, en este caso, abiertas o rotas.

${ }^{37}$ Prosifico mi lectura de estos tres versos: 'Jericó, vencida, dio sus puertas francas y sus muros rotos para que la gloriosa arca del señor prosiga triunfos'.
} 
manera más honrosa posible: los premios materiales prometidos en la convocatoria, la mayoría de plata - tazas, jarrillas, cucharas, cajas para rosario-, valiosas gratificaciones que ofrecía la Orden de la Merced por los esfuerzos líricos de los concursantes.

Por un lado, el hecho de que Alavés, el único mercedario (con la posible excepción ya comentada) cuyas apreciaciones de las tradiciones en torno a Nolasco se leen en el Libro segundo y en el cartel, utilice reiteradamente el término milagro no ha de sorprender, ya que él sería el más interesado en resaltar la presencia del milagro en la vida del santo que, como escribió Alfonso X, viene "del poder de Dios" y "por merecimiento de santidad y de bondad que haya en sí aquel por quien Dios lo hace" (190). Por otro lado, el que los poetas ganadores hayan optado por términos, quizá se podría decir, con menores implicaciones teológicas, pero que todavía insinúan la grandeza del santo y la intervención de Dios a su favor, muestra su intención de cumplir con lo que Alavés propuso, de manera implícita, en la convocatoria: que ellos representaran dignos agentes de "esta muy noble y leal ciudad mexicana que, agradecida a los amorosos afectos de los hijos de Nolasco, debe celebrar su gloria a banderas desplegadas" (¿1632?: 1).

Asimismo, lo anterior podría vincularse con un posible objetivo más amplio: mostrar que Nolasco y la orden que fundó repercutieron también en este lado del Atlántico; que la eminencia de ambos resultaba pertinente en el ámbito novohispano del mismo modo que en el europeo. Como explica Rubial: "Los criollos, deseosos de ser considerados iguales a los españoles, debían demostrar que esta tierra estaba contemplada en el plan divino como un área donde habitaba la divinidad, y tal demostración sólo era posible si constataban que Dios había obrado en ella milagros y portentos como prueba de su protección" (1999: 61). Aunque la mayoría de los prodigios, maravillas, portentos y favores a los que aluden los poetas ganadores en relación con Nolasco corresponden a la época en la que vivió el santo y, por lo tanto, no pertenecen a estas tierras, el concurso de liras representa una importantísima excepción, pues en él se insinúa que el fundador mercedario era capaz de efectuar, como intermediario entre Dios y los ciudadanos mexicanos, una demostración de Su poder y Su presencia aquí en la Nueva España.

El certamen en su totalidad, claro está, representa un testimonio aún más contundente de la gran importancia de la figura de Nolasco y de la influencia, en el México del siglo XVII, de la Orden de la Merced — que cumplió 800 años el pasado 2018-, por lo que el manuscrito del Libro segundo sirve como una valiosa fuente de información histórica, social y cultural. Asimismo, el libro nos ofrece una copiosa muestra de las tendencias y modas poéticas del momento literario en el que se inscribe, entre ellas, el gongorismo, cuyos primeros rasgos definitivos en la poesía novohispana del siglo XVII, para Dorothy Schons, se encuentran, precisamente, en el manuscrito del Libro segundo. ${ }^{38}$

38 "The first definitive gongoristic traits [in $17^{\text {th }}$ century New Spain literature] appeared in a Mexican certamen of 1633 in honor of Saint Peter Nolasco" (Schons: 25) ["Los primeros 
Es por estos motivos que emprendí la tarea de elaborar la primera edición crítica de dicho manuscrito, ya que estoy convencida de que su rescate puede ayudarnos a comprender el lugar que ocupa el certamen poético en la fiesta religiosa novohispana de la época, la trayectoria de la Orden de la Merced en la Nueva España y las particularidades del certamen de 1633. La edición se publicará, junto con un extenso estudio preliminar, próximamente en la colección "El paraíso en el Nuevo Mundo" de la editorial Iberoamericana/Vervuert.

\section{Bibliografía}

Alavés, Juan de

"Certamen poético que propone a los ingeniosos y eruditos poetas de esta muy noble y leal Ciudad de Mexico..." (Cartel de la convocatoria al certamen). México: Bernardo Calderón, ¿1632?

"Es grande el poder de la poesía". El Libro segundo de la Relación historiada de las solemnes fiestas que se hicieron en la muy noble y leal Ciudad de México al glorioso padre y esclarecido patriarca san Pedro Nolasco (1633). Madrid: Iberoamericana/Vervuert, 2019 [en prensa].

Libro primero. Relación historiada de las solemnes fiestas que se hicieron en la muy noble y leal Ciudad de México al glorioso padre y esclarecido patriarca san Pedro Nolasco. Biblioteca Nacional de México, ms. \#1799, 1633a.

Libro segundo. Relación historiada de las solemnes fiestas que se hicieron en la muy noble y leal Ciudad de México al glorioso padre y esclarecido patriarca san Pedro Nolasco. Biblioteca Nacional de México, ms. \#1799, 1633b.

\section{Alfonso X}

"Partida I, Ley CXXIV: Quantas cosas ha me[n] ester el miraglo para ser verdadero", en Las siete partidas. Edición de la Real Academia de la Historia. Madrid: Imprenta Real, 1807.

Allaria, Anthony

"St. Peter Nolasco", en The Catholic Encyclopedia. Volumen 11. New York: Robert Appleton Company, 1911. Consultado en: http://www.newadvent.org/cathen/11770b.htm [14/01/18].

\section{Beristáin de Souza, José Mariano}

Biblioteca hispanoamericana septentrional. 2a edición facsimilar. Edición de Emilio Azcárraga Milmo y Valentín Molina Piñeiro. México: Instituto de Estudios y Documentos Históricos/ Claustro de Sor Juana, 1980.

rasgos gongorinos definitivos [en la literatura novohispana del siglo XVII] aparecieron en un certamen mexicano de 1633 en honor a san Pedro Nolasco”]. Para un análisis de los rasgos gongorinos en el Libro segundo, véase el apartado del estudio preliminar de Alavés, 2019 [en prensa], titulado "El gongorismo en el certamen". 


\section{Entre milagros, prodigios, maravillas, portentos y favores}

BRIDGEs Snyder, Josey

"Delilah and Her Interpreters", en Carol Ann Newsom, Sharon H. Ringe, Jacqueline E. Lapsley (editors). Women's Bible Commentary. Louisville, Kentucky: Westminster John Knox Press, 2012, 138-141.

Cardaillac, Louis

"Erotismo y santidad", en Cahiers d'Études Romanes, número 26 (2013). Consultado en: http://etudesromanes.revues.org/3920 [07/03/17].

Cruz, sor Juana Inés de la

Obras completas. II. Villancicos y letras sacras. Edición, prólogo y notas de Alfonso Méndez Plancarte. México: Fondo de Cultura Económica, 1952.

García Gutiérrez, Pedro Francisco

"Iconografia mercedaria", en Estudios. Revista Trimestral Publicada por los Frailes de la Orden de la Merced, número 149 (1985), 9-126.

Grimal, Pierre

Diccionario de mitología griega y romana. Traducción de Francisco Payarols. Prefacio de Charles Picard. Revisión y prólogo de la edición española de Pedro Pericay. Barcelona: Labor, 1965.

"Hoy celebramos el Día de san Pedro Nolasco, fundador de la Orden de la Merced"

Provincia Mercedaria de Chile. Consultado en: http://www.mercedarios.cl/detalle.php?id= MTA2 [29/01/2016].

Lacarra Ducay, María Jesús

"Algunos milagros que nuestro Señor fizo por nuestro padre sancto Antonio: presentación del texto y aproximación tipológica", en Crisol, número 4 (2000), 215-241.

León CÁZzares, María del Carmen

Reforma o extinción. Un siglo de adaptaciones de la Orden de Nuestra Señora de la Merced en Nueva España. México: Universidad Nacional Autónoma de México, Instituto de Investigaciones Filológicas, Centro de Estudios Mayas, 2004.

LEONARD, IRVING

La época barroca en el México colonial. Traducción de Agustín Ezcurdia. México: Fondo de Cultura Económica, 1974.

Montoya, Jesús

Las colecciones de milagros de la Virgen en la Edad Media (El milagro literario). Granada: Universidad de Granada, 1981.

"Nuestra Provincia. Provincia Mercedaria Mexicana. Notas cronológicas"

Orden de la Merced, Provincia de México. Consultado en: http://www.mercedariosmexico.org/ la-orden/nuestra-provincia [13/05/2017].

OrTiZ De ZúÑiga, Diego

Anales eclesiásticos y seculares de la muy noble y muy leal ciudad de Sevilla, metrópoli de la Andalucía... Madrid: Imprenta Real, 1796. 


\section{PÉrez, Manuel}

"Sobre el carácter histórico de los milagros en la predicación del siglo XVII novohispano", en Memorabilia, número 11 (2008), 46-63.

Los cuentos del historiador. Literatura y ejemplo en una historia religiosa novohispana. Madrid/Frankfurt/México: Iberoamericana/Vervuert/Bonilla Artigas, 2012.

Presentación, fray Juan de la

Vida del glorioso padre san Pedro Nolasco, Patriarca y fundador (por divina relación) del Sacro Real, y Militar Orden de nuestra Señora de la Merced. Cádiz: Juan Lorenzo Machado, 1665.

Real Academia Española

Diccionario de Autoridades [1726-1739]. Madrid: Real Academia Española. Consultado en: http://web.frl.es/DA.html [12/12/16].

RiberA, Manuel Mariano

Real Capilla de Barcelona, la mayor y más principal de los reynos de la corona de Aragon, ilustrada y defendida a favor de nuestro gran monarca rey y señor Carlos Segundo. Barcelona: Iayme Surià, 1698.

Rubial, Antonio

La santidad controvertida: hagiografia y conciencia criolla alrededor de los venerables no canonizados de Nueva España. México: Fondo de Cultura Económica, 1999.

"Una literatura de prodigios. Textos hagiográficos y hierofánicos novohispanos del siglo xviı", en Ana Castaño, Jessica C. Locke y Jorge Gutiérrez Reyna (editores). Historia de las literaturas en México: siglos XVI al XVIII. Volumen II: Siglo XVII. México: Universidad Nacional Autónoma de México [en proceso].

Schons, Dorothy

"The Influence of Góngora on Mexican Literature during the Seventeenth Century", en Hispanic Review, número 7 (1939), 22-34.

Tenorio, Martha Lilia

Poesía novohispana. Antología. México: El Colegio de México/Fundación para las Letras Mexicanas, 2010.

Vincent-Cassy, Cécile

"Fiestas de santos, fiestas de poetas: en torno a los festejos de 1629 en honor a San Pedro Nolasco", en Pierre Civil y Françoise Crémoux (editores). Nuevos caminos del hispanismo. Actas del XVI Congreso de la Asociación Internacional de Hispanistas. Madrid: Iberoamericana/Vervuert, 2010 [CD-ROM]. Consultado en: https://cvc.cervantes.es/literatura/aih/pdf/16/ aih_16_2_134.pdf [19/11/18].

ZúÑIGa Corres, Ignacio

"La Orden de la Merced en Centroamérica: 1536-1992 (Apostolado socio-cultural-caritativo)", en Estudios. Revista Trimestral Publicada por los Frailes de la Orden de la Merced, volumen 50, número 185 (1994), 5-52. 